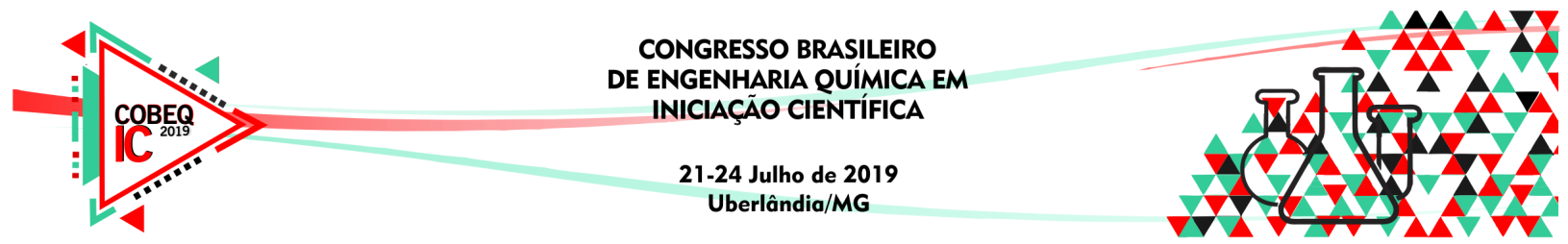

\title{
ESTUDO DO EQUILÍBRIO DE FASES DA PRECIPITAÇÃO DE QUIMOTRIPSINA COM O USO DE SAIS
}

\author{
I. M. F. JUNQUEIRA ${ }^{1}$ e E. O. WATANABE ${ }^{1}$ \\ ${ }^{1}$ Universidade Federal de Uberlândia, Faculdade de Engenharia Química \\ E-mail para contato: erika@ufu.br
}

\begin{abstract}
RESUMO - Proteínas são utilizadas em diversas aplicações, mas elas não são obtidas puras e uma sequência de etapas de separação é necessária para que se obtenha o produto desejado no nível de pureza requerido. A precipitação de proteínas com o uso de sais é bastante utilizada pela alta capacidade de concentrar a molécula de interesse e pelo seu baixo custo, constituindo mais da metade dos processos de purificação. Processos de precipitação de proteínas por "salting-out" são estudados com ênfase na solubilidade da proteína em função do tipo de sal, do $\mathrm{pH}$ e da temperatura. Nesse sentido, o estudo de equilíbrio de fases da precipitação de proteínas pode contribuir para a melhor caracterização do sólido e permitir que se determine a influência de parâmetros como $\mathrm{pH}$ e temperatura em sua estrutura. Neste trabalho, o equilíbrio de fases da precipitação de quimotripsina foi estudado por meio de ensaios de precipitação, nos quais as composições das fases coexistentes foram analisadas. Os ensaios de precipitação desta enzima foram conduzidos utilizando-se sulfato de amônio e sulfato de sódio a $5^{\circ} \mathrm{C}$ como agentes precipitantes. A composição do precipitado verdadeiro foi obtida através da intersecção de extrapolações das linhas de amarração determinadas experimentalmente, indicando a formação de um precipitado verdadeiro sólido composto apenas de proteína.
\end{abstract}

\section{INTRODUÇÃO}

O desenvolvimento de métodos e técnicas de separação e purificação de bioprodutos é essencial para os avanços da área de pesquisas biotecnológicas. O potencial de aplicação ou uso final de um bioproduto dependerá do nível de pureza, por exemplo: um alto grau de pureza é necessário para aplicações terapêuticas e um baixo grau de pureza para aplicações industriais como detergentes domésticos. A finalidade da purificação é atingir uma enzima sem contaminantes, na concentração desejada e que ela seja transportada para um ambiente a qual ela permaneça estável e pronta para ser manipulada da forma desejada. Dentre a diversidade de métodos de separação, a precipitação é uma das operações unitárias mais utilizadas em bioprocessos.

A precipitação da proteína pode ser ocasionada pela adição de sal na solução de proteína diluída em água, a qual leva à diminuição da solubilidade da proteína motivada pela dissolução do sal. Esse processo é chamado de "salting-out". Na solução, os íons formados competem com a proteína pelas moléculas de água e após a remoção da camada de hidratação, a interação proteína-proteína, principalmente, as ligações hidrofóbicas prevalecem na solução (Ladisch, 2001). 


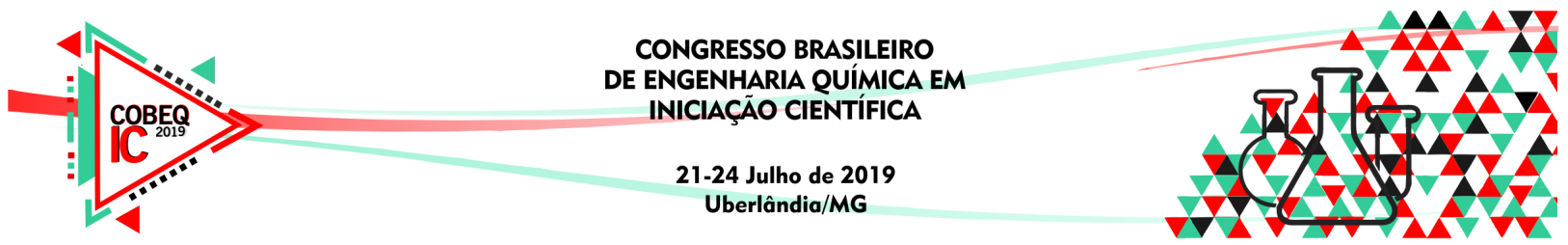

Processos de precipitação de proteínas por "salting-out" têm sido estudados destacandose a solubilidade da proteína em função de parâmetros como o tipo de sal, $\mathrm{pH}$ e temperatura (Shih et al., 1992; Cheng et al., 2006, Maurer et al., 2011). No entanto, a determinação da composição completa das fases em equilíbrio (proteína, sal e água) raramente é realizada. Nesse sentido, o estudo de equilíbrio de fases da precipitação de proteínas pode contribuir para a melhor caracterização do sólido e permitir que se determine a influência de parâmetros como $\mathrm{pH}$ e temperatura em sua estrutura. Os diagramas de fases de sistemas contendo proteínas apresentam as composições das diferentes fases em equilíbrio em função de parâmetros como $\mathrm{pH}$, temperatura e tipo de sal, o que possibilita a escolha de condições e sistemas com elevada quantidade do sólido desejado no precipitado. A escolha desta melhor condição do sistema permite menor custo do processo, redução do número de etapas de purificação subsequentes e menor quantidade de produto desejado na fase sobrenadante a ser tratada ou levada para descarte (Moretti et al., 2000).

Por essas razões, este trabalho trata do equilíbrio de fases da precipitação de soluções proteicas com sais, o que inclui o estudo da determinação completa do diagrama de fases, contendo dados de concentração de todos os componentes presentes no sistema.

A proteína a ser utilizada neste projeto é a quimotripsina suína, enzima proteolítica pertencente à família das serino proteases. A quimotripsina é estável a $\mathrm{pH} 3,0$ e possui massa molecular igual a $25,7 \mathrm{kDa}$ (Barret et al., 1998). As serino proteases participam da digestão, formação e dissolução de coágulos do sangue, em imunorreações a organismos e células externas e na fertilização de óvulos. Além disso, a quimotripsina é bastante utilizada nas indústrias farmacêutica e alimentícia e requerida em grande quantidade, por isso a necessidade de entendimento dos processos de separação, para a sua produção em larga escala (Boeris et al., 2009). A relativa disponibilidade dessa proteína, a alta solubilidade da quimotripsina em água e a necessidade de purificação para aplicação em larga escala motivam o uso dessa proteína neste estudo de equilíbrio de fases da precipitação por "salting-out".

Os sais a serem utilizados serão o sulfato de amônio e sulfato de sódio. A efetividade dos sais na precipitação de proteínas por "salting-out" depende fortemente do tipo do sal utilizado.

\section{MATERIAL E MÉTODOS}

\subsection{Material}

A proteína quimotripsina bovina foi gentilmente decida pela Biobrás S.A. O sal sulfato de amônio ( $99 \%$ de pureza) foi adquirido da Vetec e o sulfato de sódio ( $99 \%$ de pureza) foi adquirido da Merck.

\subsection{Métodos}

Preparo das soluções de proteína e sal: Solução de quimotripsina bovina foi preparada em concentração mássica de $15 \mathrm{~g} / \mathrm{g}$ de água. Os sais sulfato de amônio e sulfato de sódio foram preparados em concentrações mássicas de $40 \mathrm{~g} / \mathrm{g}$ de água e $20 \mathrm{~g} / \mathrm{g}$ de água, respectivamente. 


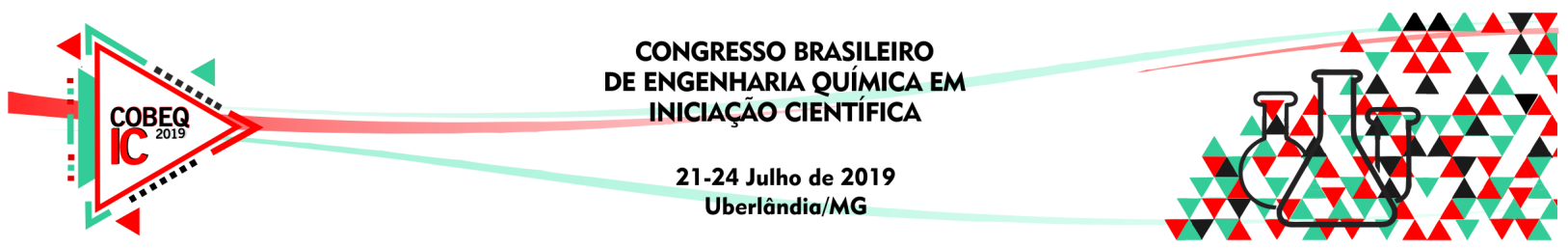

Precipitação das proteínas: A precipitação das proteínas foi realizada segundo um protocolo que consistiu em adicionar diferentes massas de solução de sal gota a gota a diferentes massas de solução de proteína contidas em tubos de centrífuga, de modo a produzir $4 \mathrm{~g}$ de uma mistura de composição desejada. A seguir, a mistura foi mantida à temperatura constante de $5^{\circ} \mathrm{C} \mathrm{em}$ banho termostático por 24 horas. Após este tempo, a fase sobrenadante e o precipitado foram separados por centrifugação a $2000 \mathrm{~g}$ e temperatura controlada de $5^{\circ} \mathrm{C}$ até a separação das fases por aproximadamente 2 horas. Com o auxílio de uma seringa, a fase sobrenadante foi retirada e medida de massa dessa fase foi realizada, enquanto que o precipitado permaneceu no tubo de centrífuga, para posterior dissolução em água e determinação dos componentes dessa mistura sólida.

Determinação das concentrações de proteína, água e sal na fase sobrenadante e precipitado: Para a determinação da concentração de proteína na fase sobrenadante, uma alíquota desta fase foi diluída em água e medidas de absorbância a $280 \mathrm{~nm}$ foram realizadas. A determinação da quantidade de sal sulfato de amônio e sulfato de sódio na fase sobrenadante foi realizada por condutividade. Para a determinação da quantidade de sal por condutividade, uma curva de calibração de condutividade em função da concentração do sal foi preparada. $\mathrm{O}$ efeito da concentração de proteína na medida de condutividade do sal foi avaliado e considerado desprezível. A determinação da quantidade de água na fase sobrenadante foi obtida através de balanços de massa. O precipitado mantido no tubo de centrífuga, após a retirada da fase sobrenadante, foi dissolvido em água e medidas de absorbância a $280 \mathrm{~nm}$ foram realizadas. A determinação das quantidades de água e de sal da fase precipitado foi obtida através de balanços de massa.

\section{RESULTADOS E DISCUSSÃO}

\subsection{Equilíbrio de fases}

$\mathrm{O}$ equilíbrio de fases sólido-líquido dos sistemas quimotripsina - sal - água a $5^{\circ} \mathrm{C}$ é apresentado nas Tabelas 1 e 2. As concentrações dos componentes quimotripsina, sal e água na alimentação, na fase sobrenadante e na fase precipitado foram determinadas e são apresentadas em fração mássica (g componente/g fase). A incerteza experimental envolvida na determinação de quimotripsina foi entre 0,0001 (para baixas concentrações de proteína) e 0,002 (para altas concentrações de proteína); e a incerteza envolvida na concentração de sal foi entre 0,003 (para baixas concentrações de sal) e 0,02 para altas concentrações de sal.

Os resultados indicaram que a quantidade de quimotripsina na fase sobrenadante diminuiu com o aumento da quantidade de sal na fase sobrenadante, evidenciando o efeito "salting-out" da precipitação da quimotripsina, como era esperado segundo a literatura (Scopes, 1994; Ladisch, 2001; Watanabe et al., 2006). Notou-se também que as concentrações de sal na fase precipitado foram menores do que na fase sobrenadante, indicando uma separação desigual da quantidade de sal entre as fases. Este comportamento não é frequentemente considerado nos estudos de equilíbrio de fases de soluções proteicas, os quais descrevem o precipitado como uma fase sólida de proteína pura.

Estes resultados mostraram que a fase precipitado obtida é na realidade uma mistura da proteína e do sal que inevitavelmente acompanha a quimotripsina, o que corrobora com os 


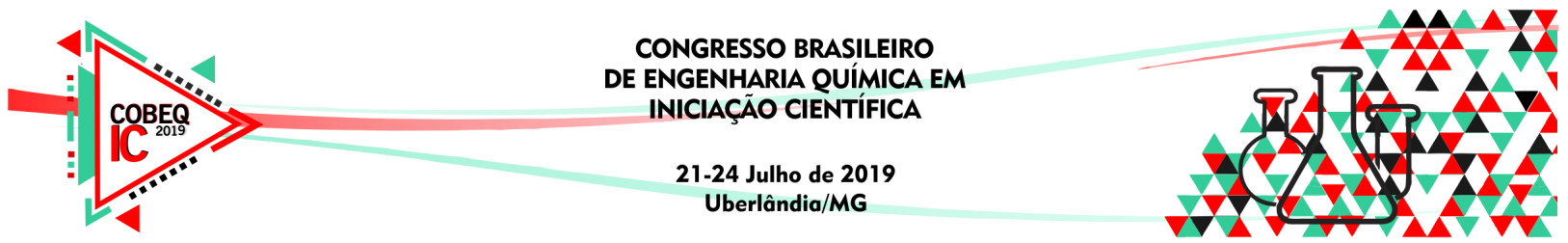

resultados apresentados Shih et al. (1992) para lisozima com os sais cloreto de sódio, sulfato de sódio e fosfato de sódio.

Tabela 1 - Sistema quimotripsina (1) - sulfato de amônio (2) - água (3) a $5^{\circ} \mathrm{C}$ : concentrações mássicas dos componentes na alimentação expressas em $\mathrm{g}$ componente/g solução.

\begin{tabular}{|c|c|c|c|c|c|c|c|c|}
\hline \multicolumn{3}{|c|}{$\begin{array}{c}\text { Fração mássica dos } \\
\text { componentes (i) na } \\
\text { alimentação }\end{array}$} & \multicolumn{3}{c|}{$\begin{array}{c}\text { Fração mássica dos } \\
\text { componentes (i) na fase } \\
\text { sobrenadante }\end{array}$} & \multicolumn{3}{c|}{$\begin{array}{c}\text { Fração mássica dos } \\
\text { componentes (i) na fase } \\
\text { precipitado }\end{array}$} \\
\hline$(1)$ & $(2)$ & $(3)$ & $(1)$ & $(2)$ & $(3)$ & $(1)$ & $(2)$ & $(3)$ \\
\hline 0,0234 & 0,3420 & 0,6345 & 0,0008 & 0,3542 & 0,6451 & 0,0739 & 0,3144 & 0,6106 \\
\hline 0,0442 & 0,2861 & 0,6697 & 0,0010 & 0,3095 & 0,6895 & 0,0918 & 0,2578 & 0,6460 \\
\hline 0,0645 & 0,2314 & 0,7042 & 0,0052 & 0,2471 & 0,7477 & 0,1248 & 0,2145 & 0,6577 \\
\hline 0,0856 & 0,1744 & 0,7400 & 0,0196 & 0,1865 & 0,7940 & 0,2262 & 0,1474 & 0,6200 \\
\hline 0,1061 & 0,1190 & 0,7749 & 0,0821 & 0,1256 & 0,7923 & 0,2400 & 0,0842 & 0,6825 \\
\hline 0,1293 & 0,0564 & 0,8143 & 0,1090 & 0,0584 & 0,8326 & 0,3000 & 0,0397 & 0,6630 \\
\hline
\end{tabular}

Tabela 2 - Sistema quimotripsina (1) - sulfato de sódio (2) - água (3) a $5^{\circ} \mathrm{C}$ : concentrações mássicas dos componentes na alimentação expressas em g componente/g solução.

\begin{tabular}{|c|c|c|c|c|c|c|c|c|}
\hline \multicolumn{3}{|c|}{$\begin{array}{c}\text { Fração mássica dos } \\
\text { componentes (i) na } \\
\text { alimentação }\end{array}$} & \multicolumn{3}{c|}{$\begin{array}{c}\text { Fração mássica dos } \\
\text { componentes (i) na fase } \\
\text { sobrenadante }\end{array}$} & \multicolumn{3}{c|}{$\begin{array}{c}\text { Fração mássica dos } \\
\text { componentes (i) na fase } \\
\text { precipitado }\end{array}$} \\
\hline$(1)$ & $(2)$ & $(3)$ & $(1)$ & $(2)$ & $(3)$ & $(1)$ & $(2)$ & $(3)$ \\
\hline 0,0284 & 0,1572 & 0,8144 & 0,0075 & 0,1608 & 0,8317 & 0,1000 & 0,1436 & 0,7483 \\
\hline 0,0512 & 0,1220 & 0,8268 & 0,0166 & 0,1322 & 0,8512 & 0,2001 & 0,0747 & 0,7138 \\
\hline 0,0696 & 0,0936 & 0,8368 & 0,0220 & 0,0982 & 0,8798 & 0,2711 & 0,0728 & 0,6403 \\
\hline 0,0884 & 0,0647 & 0,8469 & 0,0313 & 0,0652 & 0,9034 & 0,3036 & 0,0626 & 0,6263 \\
\hline 0,1117 & 0,0287 & 0,8596 & 0,0764 & 0,0285 & 0,8951 & 0,2524 & 0,0296 & 0,7130 \\
\hline
\end{tabular}

$\mathrm{O}$ equilíbrio de fases dos sistemas quimotripsina - sal - água a $5^{\circ} \mathrm{C}$ pode também ser representado na forma de diagramas de fase (Figuras 1 e 2). Os diagramas de fase apresentam as composições de quimotripsina, sal e água na alimentação e nas fases sobrenadante e precipitado em equilíbrio a temperatura constante de $5^{\circ} \mathrm{C}$.

As composições da fase sobrenadante e do precipitado que coexistem em equilíbrio na precipitação de quimotripsina podem ser conectadas por linhas de amarração. Devido a uma separação necessariamente incompleta da fase sobrenadante e do precipitado, é razoável assumir que a fase sobrenadante não contém precipitado, mas o precipitado contém quantidades apreciáveis de fase sobrenadante. Assim, o precipitado é uma mistura da fase sobrenadante e do precipitado proteico sólido, que chamaremos de precipitado verdadeiro. A composição deste precipitado verdadeiro deve estar sobre as linhas que conectam a fase 


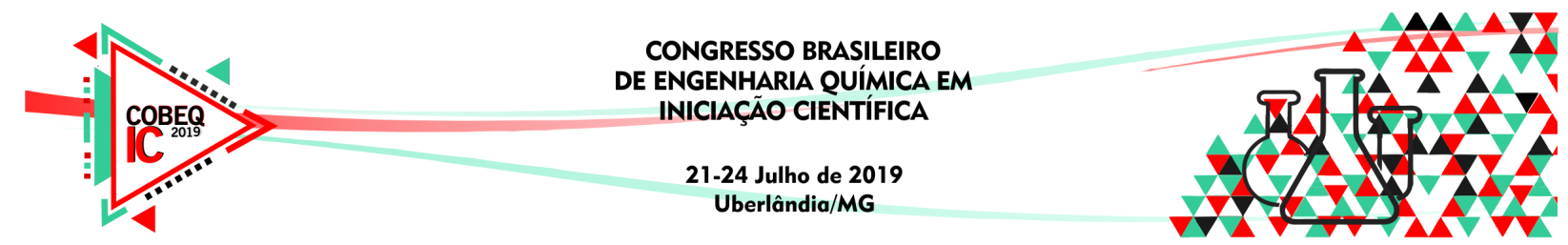

sobrenadante e o precipitado. Assim, extrapolando-se as linhas de amarração no diagrama de fase, verificou-se que estas se encontram em um único ponto, que se propõe neste trabalho que seja a composição da fase sólida formada (Watanabe et al., 2009). Neste trabalho, verificou-se que as extensões das linhas de amarração encontravam-se em um único ponto, diferentemente do que ocorre com o sistema lisozima - sulfato de amônio - água reportado por Popova et al. (2008), que possui dois precipitados verdadeiros. O precipitado verdadeiro encontrado neste trabalho é um sólido amorfo composto apenas de proteína, independentemente do sal utilizado (sulfato de amônio e sulfato de sódio).

Figura 1 - Diagramas de fases do sistema quimotripsina-sulfato de amônio-água a $5,0^{\circ} \mathrm{C}$. Composição da alimentação $(\square)$, composição da fase sobrenadante $(\triangle)$, composição da fase precipitado (O); linhas de amarração (一).

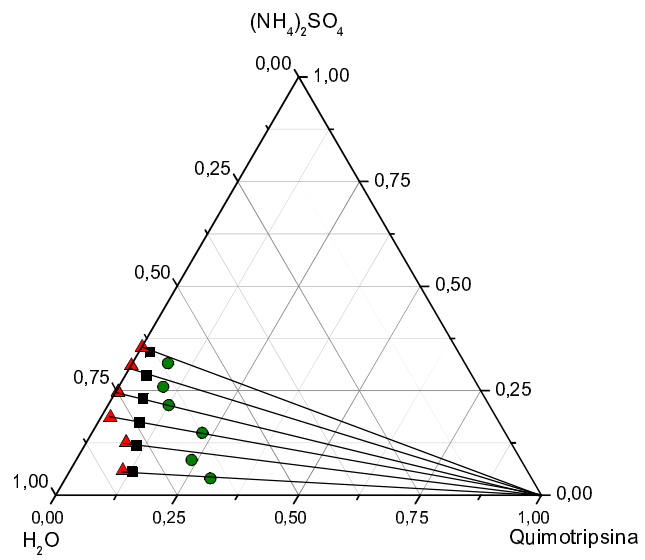

Figura 2 - Diagrama de fases do sistema quimotripsina-sulfato de sódio-água a $5,0^{\circ} \mathrm{C}$.

Composição da alimentação $(\square)$, composição da fase sobrenadante $(\triangle)$, composição da fase precipitado (O); linhas de amarração (一).

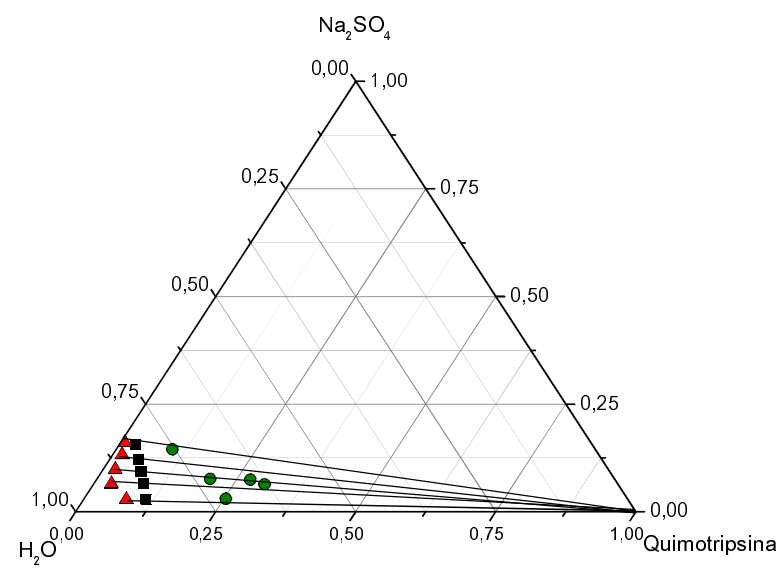

\section{CONCLUSÃO}

Neste trabalho foi realizado o estudo do equilíbrio de fases da quimotripsina precipitada com a adição dos sais sulfato de amônio e sulfato de sódio a $5^{\circ} \mathrm{C}$. Os resultados permitiram 


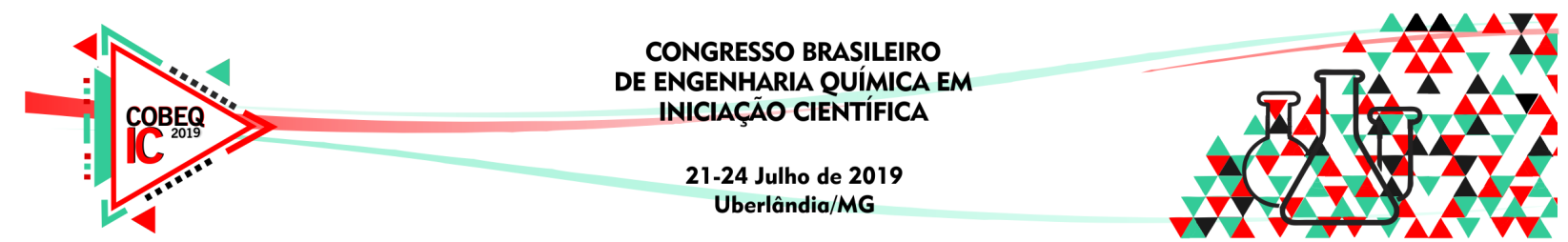

evidenciar o efeito "salting-out", assim como a partição desigual do sal entre as fases, mostrando que a fase precipitado é uma mistura de sal, proteína e água. Os diagramas de fase da precipitação de quimotripsina nos diferentes sais indicaram a presença de um único precipitado verdadeiro, composto apenas de proteína. O uso desta técnica na análise de diagramas de fases pode possibilitar a escolha do sistema mais adequado para a obtenção da fase sólida desejada, uma modelagem termodinâmica mais adequada e a avaliação da eficiência da separação sólido-líquido através da composição do sólido formado.

\section{REFERÊNCIAS}

BARRET, A.J., RAWLINGS, N.D., WOESSNER, J.F. Handbook of Proteolitic Enzymes, San Diego, Academic Press, 1998.

BOERIS, V., ROMANINI, D., FARRUGGIA, B., PICÓ, G. Purification of chymotrypsin from bovine pancreas using precipitation with a strong anionic polyelectrolyte, Process Biochem., v. 44, p. 588-592, 2009.

CHENG, Y-C., LOBO, R.F., SANDLER, S.I., LENHOFF, A.M. Kinetics and equilibria of lysozyme precipitation and crystallization in concentrated ammonium sulfate solutions, Biotechnol. Bioeng., v. 94, p. 177-188, 2006.

LADISCH, M.R. Bioseparations Engineering. New York, John Wiley \& Sons, 2001.

MAURER, R. W., SANDLER, S. I., LENHOFF, A. M. Salting-in characteristics of globular proteins, Biophys. Chem., v. 156, p. 72-78, 2011.

MORETTI J. J., SANDLER, S. I., LENHOFF, A. M., Phase equilibria in the lysozymeammonium sulfate-water system. Biotechnol. Bioeng., v. 70, p. 498-506, 2000.

POPOVA, E.; WATANABE, E.O.; PESSÔA FILHO, P.A.; MAURER, G. Phase equilibria for salt-induced lysozyme precipitation: effect of salt concentration and $\mathrm{pH}$. Chem. Eng. Process., 47, 1026-1033, 2008.

SCOPES, R. K. Protein Purification. New York: Springer-Verlag New York Inc., 3th ed., 1994.

SHIH, Y.C., PRAUSNITZ, J.M., BLANCH, H.W. Some characteristics of protein precipitation by salts, Biotechnol. Bioeng., v. 40, p. 1155-1164, 1992.

WATANABE, E.O.; POPOVA, E.; MIRANDA, E.A.; MAURER, G.; PESSÔA FILHO, P.A. Phase equilibria for salt-induced lysozyme precipitation: effect of salt type and temperature, Fluid Phase Equilib., p. 281, 32-39, 2009.

WATANABE, E.O., PESSÔA FILHO, P.A., MIRANDA, E.A., MOHAMED, R.S. Evaluation of the use of volatile electrolyte system produced by ammonia and carbon dioxide in water for the salting-out of proteins: precipitation of porcine trypsin. Biochem. Eng. J., v. 30, p. 124-126, 2006. 